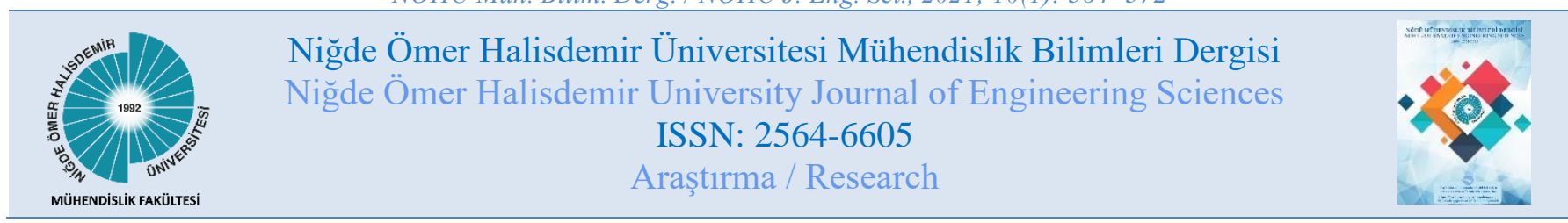

\title{
Design and development of an autonomous bicycle
}

\section{Otonom bir bisikletin tasarımı ve geliştirilmesi}

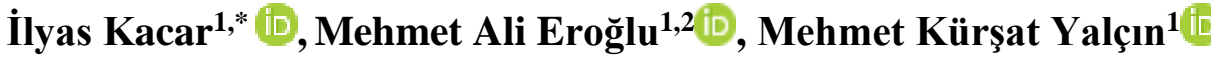 \\ ${ }^{1}$ Department of Mechatronics Engineering, Niğde Ömer Halisdemir University, Nigde 51240, Turkey \\ ${ }^{2}$ Technical Sciences Vocational School, Niğde Ömer Halisdemir University, Nigde 51240, Turkey
}

\begin{abstract}
In this study; a design to build study has been carried out for a self-balancing bicycle. Also support and rising up systems to bring it the equilibrium position in case of its fall are added. Finite element simulation of the bicycle frame is performed to get its dynamics and structural responses. Finally, an autonomous bicycle frame with self-balancing capability is designed. Self-balancing has been performed by means of a control momentum gyroscope including a single axis gimbal. The performance of the design has been evaluated for varying loading, driving speed and torque conditions. Implementation of this study with control algorithms will be performed as a future work.
\end{abstract}

Keywords: Autonomous navigation, Balancing, Gyroscope, Flywheel, Control momentum gyroscope

\section{Introduction}

Unmanned air, land, marine and under water vehicles are called autonomous vehicles. They detect, collect, and transmit data wirelessly to headquarters. For autonomy, single track vehicles like bicycles require not only unmanned driving but also robotic balancing [1,2] Autonomous driving requires more accuracy on self-balancing. Single track vehicles need active balancing during its driving because they have unstable equilibrium position while driving. This study focuses on design and mechanical analysis of self-balancing and rising up mechanisms of a two-wheeled bicycle.

It is seen that there are four types of self-balancing method for a bicycle [3], such as control momentum gyroscope (CMG) [4], mass balancing [5], use of steering control [6], and using reaction wheels/spheres [7]. Indeed, CMG's and reaction wheels are the same mechanically, but reaction wheels work at lower speed and provide less momentum while CMG's work at higher speed and can deliver more momentum. Both transfer angular momentum. The direction of angular momentum vector can be changed by changing the rotation vector's direction of the spinning rotor in gimbal system of CMGs. Consequently, any change in angular momentum leads to a gyroscopic reaction torque, known as "precession". The gyroscopic precession torque is used to provide the required balancer torque for self-balancing vehicles. Since CMGs bring gyroscopic effects onto the system dynamics, the interaction of gimbal and bicycle frame plays important role on gyroscopic system designs. Also a successful controller design depends on that interaction. In this study, CMG is chosen due to its short response time and the ability to produce a great amount of
Özet

Bu çalışmada; kendi kendini dengeleyebilen bir bisiklet için bir tasarım çalıșması yapılmıștır. Ayrıca düșmesi durumunda denge konumuna getirmek için destek ve kaldırma sistemleri eklenmiştir. Sonlu eleman simülasyonu yapılarak, bisiklet çerçevesinin dinamikleri ve yapisal tepkileri elde edilmiştir. Netice olarak, kendi kendini dengeleme özelliğine sahip otonom bir bisiklet tasarlarımı gerçekleştirilmiştir. Kendinden dengeleme, tek eksenli bir gimbal içeren kontrol torku jiroskopu ile gerçekleştirilmiştir. Tasarımın performansı değişen yükleme, sürüş hızı ve sürüş torku açısından değerlendirilmiştir. Bu çalışmanın kontrol algoritmaları ile uygulanması müteakip çalışma olarak planlanmıştır.

Anahtar kelimeler: Otonom navigasyon, Dengeleme, Jiroskop, Volan, Kontrol momentum jiroskopu

balancing torque which is suitable for self-balancing bicycles.

It is seen that new solutions are based on gyros on selfbalancing and autonomous navigation [8]. CMGs are firstly implemented in 1960s to control the attitude of the satellite bodies [9] up to $30 \mathrm{~kg}$ due to precise and fast attitude maneuvering capability [10]. Nowadays, CMGs have been used as single or in multiple configurations for different applications including balancing of bicycles' frames.

But CMGs have control difficulties, besides, higher power consumption and vibration due to continuous spinning of its flywheel [11]. Some strategies are applied to overcome control issues [12-14]. Optimal design studies are presented for minimum power consumption [15, 16]. Mutually-working double CMG configurations provide the gyroscopic torque twice and cancel out the unwanted moments and vibrations [17].

In the light of previous researches, it is seen that using CMGs is a reasonable choice since they provide a large amount of gyroscopic torque, they don't need any contact with earth ground for action, and their stability is maintained even if they don't move $[18,19]$. So, experiences cause us to investigate the parameters which are effective on gyroscopic moment on various design alternatives for a two-wheeled bicycle. The aim of this study is to build a self-balancing system design based on a single-gimbal $\mathrm{CMG}$ for a two-wheeled bicycle. Its implementation onto an autonomous two-wheeled bicycle and control issues are in our future study plan. Finite element simulations are performed to obtain structural responses and to investigate its dynamics. Parameters from a real bicycle frame are used to constitute the finite element model.

\footnotetext{
* Sorumlu yazar / Corresponding author, e-posta / e-mail: ikacar@ gmail.com (İ. Kacar)

Geliş / Recieved: 02.10.2019 Kabul / Accepted: 25.11.2020 Yayımlanma / Published: 15.01.2021

doi: 10.28948/ngumuh.628580
} 


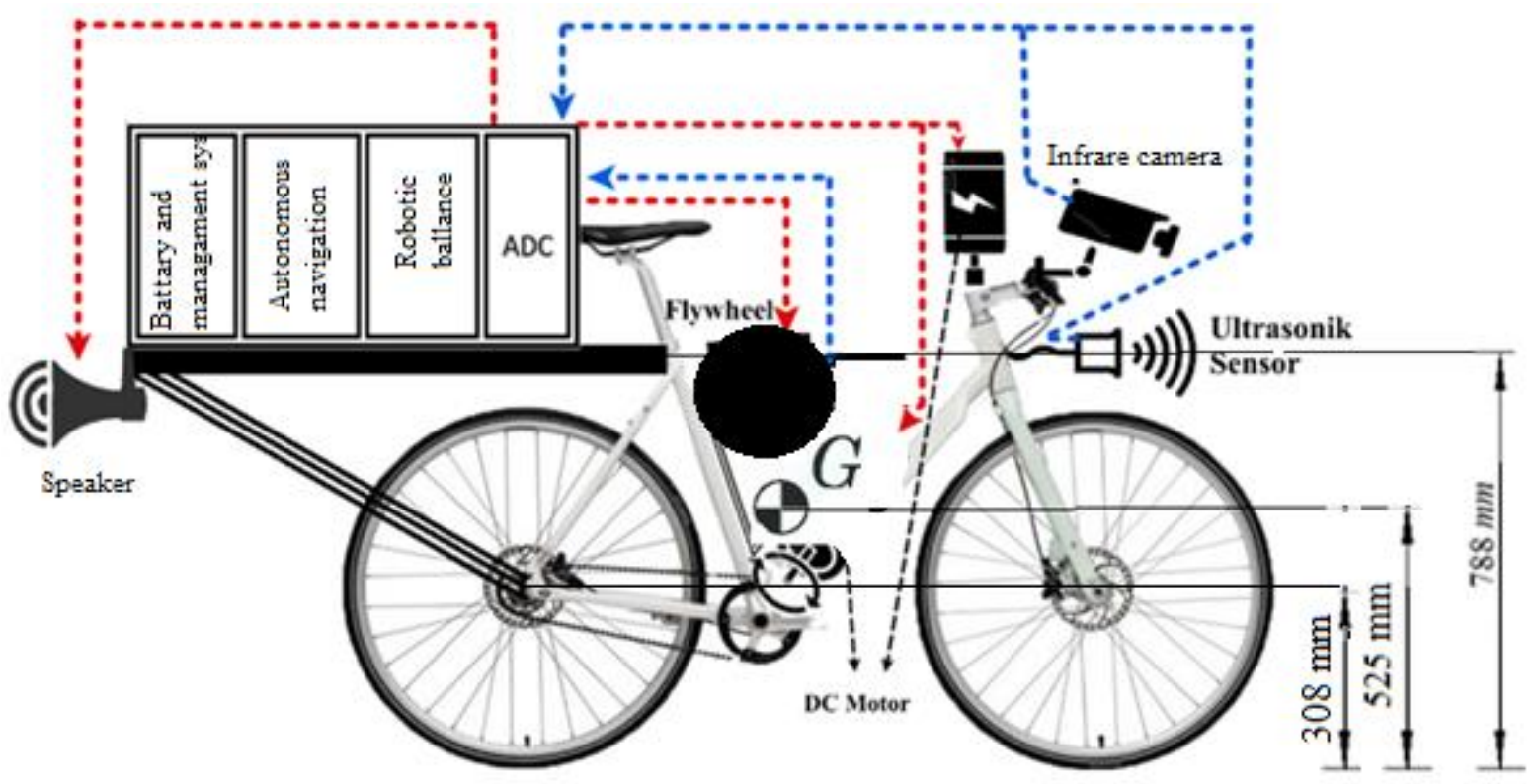

Figure 1. Part layout

Relationships between gyroscopic moment and load, driving torque, spin, stability angle are determined. Simulation results show the performance of active balancing for the bicycle. Relation between driving torque and gimbal torque is determined. Also front or rear wheel's effects on the gyroscopic torque is investigated.

\section{Materials and methods}

Relations between gyroscopic torque and load, driving torque, spin, stability angle are studied on a conceptual design by considering the effect of driving wheel and orientation of the CMG's gimbal on a riderless bicycle frame. Design alternatives for supporting and rising up are analyzed.

\subsection{Conceptual design}

A part layout including mechanic and electronic subsystems is seen in Figure 1 for the self-balancing two-wheeled riderless bicycle. Technical specifications used for calculations are based on a mountain bike's frame and given in Table 1.

Table 1. Parameters for static bicycle

\begin{tabular}{|c|c|c|c|}
\hline Parameter & Description & Value & Unit \\
\hline$m_{b}$ & The mass off the bicycle frame & 17.5 & $k g$ \\
\hline$m_{L}$ & Additional mass on bicycle & 5 & $k g$ \\
\hline$L$ & $\begin{array}{l}\text { Height of frame in reference } \\
\text { with ground }\end{array}$ & 788 & $m m$ \\
\hline$L_{G}$ & $\begin{array}{l}\text { Height of gravity center }(\mathrm{CG}) \text { in } \\
\text { reference with ground }\end{array}$ & 525 & $m m$ \\
\hline$I_{b}$ & $\begin{array}{l}\text { Mass moment of inertia with } \\
\text { respect to the wheel-ground }\end{array}$ & 1.61 & kg. $\mathrm{m}^{2}$ \\
\hline
\end{tabular}

\subsection{Background on $C M G$}

When a flywheel rotating around its main axis with a rotational velocity $\mathbf{P}$ is disturbed by another rotation namely precession (or gimbal angular velocity $\boldsymbol{\Omega}=\dot{\boldsymbol{\psi}}$ ) about its any other axis perpendicular to the direction vector of $\mathbf{P}$, a gyroscopic reaction torque $\mathbf{M}$, known as gimbal torque, arises as shown in Figure 2. The direction of the gyroscopic gimbal moment vector is orthogonal to the plane where $\mathbf{P}$ and $\boldsymbol{\Omega}$ are inside.

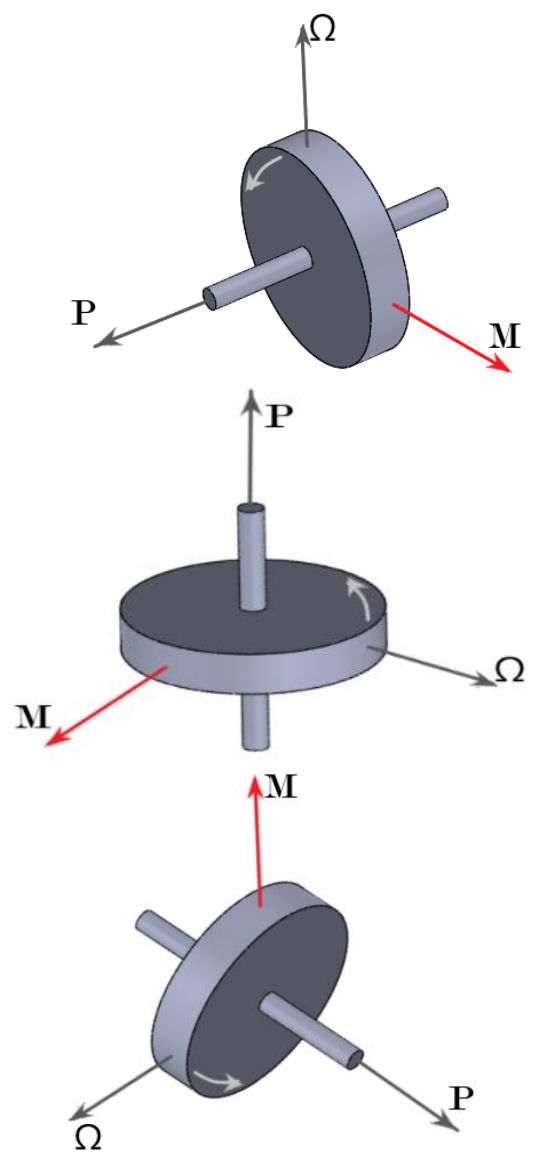

Figure 2. Gyroscopic gimbal moment vectors for various flywheel orientations 
In CMG design, it is necessary to know the angular velocity and angular momentum of the flywheel. In the Figure 3 , it is seen that a rotating flywheel has a new position after disturbing by a rotation around $Y$ axis in $\theta$ angle and $\dot{\psi}$ precession velocity while its initial position is located on $Z$ axes. $X, Y, Z$ are axes on fixed coordinate system and $x, y, z$ are new axes on rotated position. $\phi, \theta, \psi$ shows Euler angles.

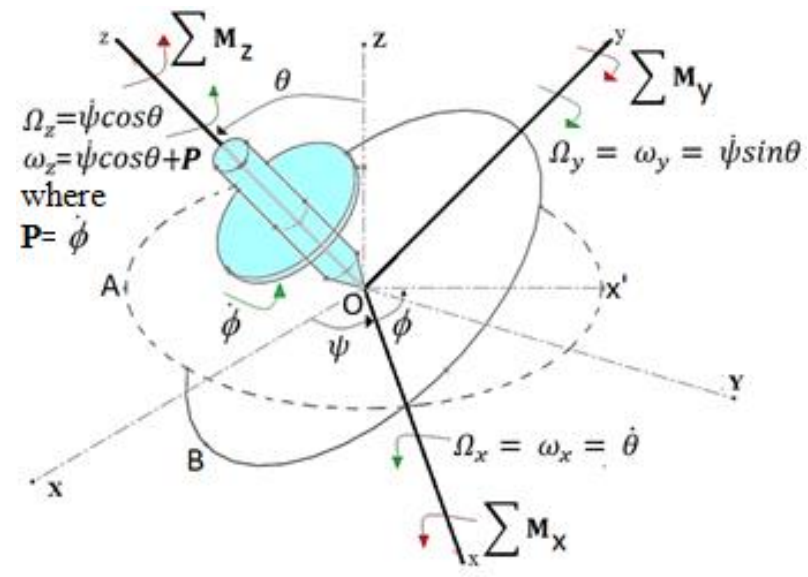

Figure 3. Vector diagram

While the flywheel's own rotational velocity components are $\omega_{x}, \omega_{y}, \omega_{z}$; the rotational velocity components of the $x$, $y, z$ axes become $\Omega_{x}, \Omega_{y}, \Omega_{z}$ and written as shown in Eq. (1) [20].

$$
\begin{gathered}
\Omega_{x}=\omega_{x}=\dot{\theta} \\
\Omega_{y}=\omega_{y}=\dot{\psi} \sin \theta \\
\Omega_{z}=\dot{\psi} \cos \theta \quad \omega_{z}=\dot{\psi} \cos \theta+\boldsymbol{P} \\
\text { where } \mathbf{P}=\dot{\varnothing}
\end{gathered}
$$

It should be noted that unlike the rotational velocity components in the $x$ and $y$ axes of the flywheel, the $z$ component also has an additional term depending on the spin P. The angular momentum components $H_{x}, H_{y}, H_{z}$ can be written by using Equation (2).

$$
\begin{gathered}
H_{x}=I_{x x} \omega_{x}=I_{0} \dot{\theta} \\
H_{y}=I_{y y} \omega_{y}=I_{0} \dot{\psi} \sin \theta \\
H_{z}=I_{z z} \omega_{z}=I(\dot{\psi} \cos \theta+\boldsymbol{P})
\end{gathered}
$$

where $I z z=I$ represents the polar moment of inertia with respect to the center of rotation about $O$, and $I x x=I z z=I_{0}$ indicates the moment of inertia about the principal axes. In the most general sense, there is a relation between angular momentum $\mathbf{H}$ and moment as $\sum \mathbf{M}=\dot{\mathbf{H}}$. The equation is defined with respect to the fixed coordinate system. Considering the rotated coordinate system, it becomes $\sum \boldsymbol{M}=\dot{\boldsymbol{H}}+\boldsymbol{\Omega} \times \mathbf{H}$. Its Cartesian form is given in Equation (3).

$$
\begin{aligned}
\sum \mathbf{M}= & \left(\dot{H}_{x}-H_{y} \Omega_{z}+H_{z} \Omega_{y}\right) \mathbf{i} \\
& +\left(\dot{H}_{y}-H_{z} \Omega_{x}+H_{x} \Omega_{z}\right) \mathbf{j} \\
& +\left(\dot{H}_{z}-H_{x} \Omega_{y}+H_{y} \Omega_{x}\right) \mathbf{k}
\end{aligned}
$$

Substitution the rotational velocity and momentum components into Equation (3), the gyroscopic gimbal moment exerted on the $x, y, z$ axes can be found as in Equation (4).

$$
\begin{gathered}
\sum M_{X}=I_{0}\left(\ddot{\theta}-\dot{\psi}^{2} \sin \theta \cos \theta\right)+I \dot{\psi}(\dot{\psi} \cos \theta \\
+\boldsymbol{P}) \sin \theta \\
\sum M_{Y}=I_{0}(\ddot{\psi} \sin \theta+2 \dot{\psi} \dot{\theta} \cos \theta) \\
-I \dot{\theta}(\dot{\psi} \cos \theta+\boldsymbol{P}) \\
\sum M_{Z}=I \frac{d}{d t}(\dot{\psi} \cos \theta+\boldsymbol{P})
\end{gathered}
$$

where $\ddot{\theta}$ and $\ddot{\psi}$ are second derivative of rotations corresponding rotational accelerations about $y$ and $x$ axes respectively. $\frac{d}{d t}$ shows time derivation. If the rotor has a constant spin speed $\mathbf{P}$, the angle of precession $\boldsymbol{\theta}$ is constant, and the frame is in static equilibrium, a particular case corresponding the single-gimbal CMG occurs where there is just one rotation component in the axis $(z)$. It is expressed in Equation (5).

$$
\begin{gathered}
\dot{\psi}=\text { constant, } \ddot{\psi}=0 \\
\theta=\text { constant, } \dot{\theta}=\ddot{\theta}=0 \\
\boldsymbol{P}=\text { constant }, \dot{\boldsymbol{P}}=0
\end{gathered}
$$

For this particular case, the $y$ and $z$ components of the moment will be zero. Thus, Eq. (4) becomes as in Eq. (6).

$$
\begin{gathered}
\sum M_{X}=\dot{\psi} \sin \theta\left[I(\dot{\psi} \cos \theta+P)-I_{0} \dot{\psi} \cos \theta\right] \\
\sum M_{Y}=0 \\
\sum M_{Z}=0
\end{gathered}
$$

This formula will be used to calculate the gyroscopic moment on a single-gimbal CMG. Equation (6) mean that a flywheel rotating around the $z$ axis in a static equilibrium does not generate any gimbal moment on the $y$ and $z$ axes. In addition, for the constant values of $\theta, \dot{\psi}$ and $p$, the magnitude of the gimbal moment $M_{X}$ becomes constant. Its direction becomes perpendicular to the $y-z$ plane.

\subsection{CMG mounting on the bicycle frame}

A single gimbal gyroscope will be enough to make the bicycle stabilized. However, the mounting location and orientation of the gyroscope will affect the gimbal moment to be transferred to the frame. Figure 4 shows two suitable installation alternatives schematically. Both are fit for stabilization. The spin, precession, and gimbal moment to balance the bicycle are also shown. It is seen that the mounting schema in Figure 4 (b) has been studied mostly $[17,21,22]$.

\subsection{Automatic support and rising-up}

In case of unrecoverable wobbling, tilting or completely falling over, support and rising up mechanisms are required to bring the bicycle back to its equilibrium position 
riderlessly. Mechanisms based on pinion-rack gear and pinned levers driven by pneumatic pistons are investigated. Whichever will be used, both must provide rotation on its longitudinal axis only during rising up. That requirement is satisfied as long as the frame doesn't lost not only force but also moment balance during rising up. Power requirements are calculated for simple comparison with each other. Figure 4 shows two available configurations to produce the gimbal moment directed along the main axis of the bicycle. The figures include just conceptual designs which will be re-designed in relation with the simulation results.

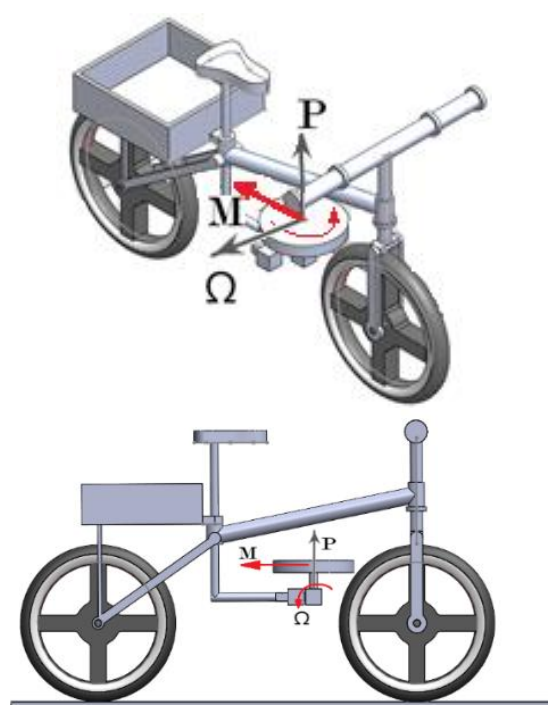

(a)
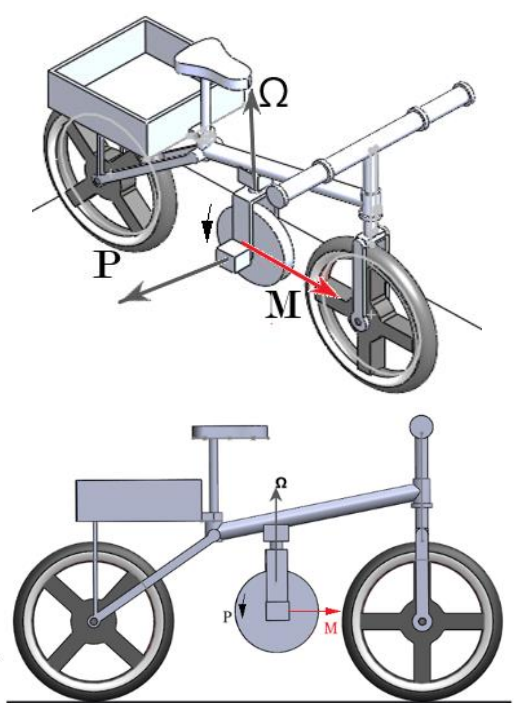

(b)

Figure 4. Mounting alternatives of a single gimbal CMG on a bicycle frame (a) Horizontal installation (b) Vertical installation

\subsubsection{Pinion-rack gear mechanism}

Two telescopic (linearly expandable) auxiliary bars are attached on both side of the frame by revolute joints which gives rotation DOF (degree of freedom) to bar as shown in Figure 5. While that DOF is driven by a ball-screw mechanism, the telescopic movement is obtained by a pinion-rack gear mechanism. They can be mounted separately on anywhere on the bicycle frame to ensure that the rotation will be about the longitudinal axis only.

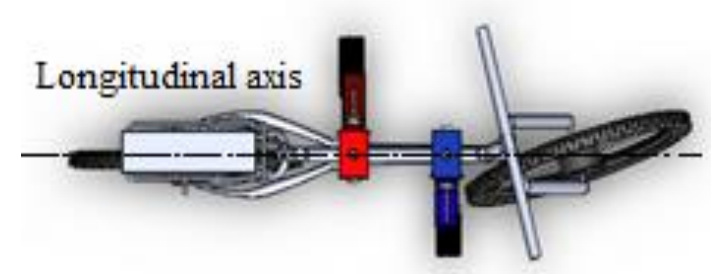

(a)

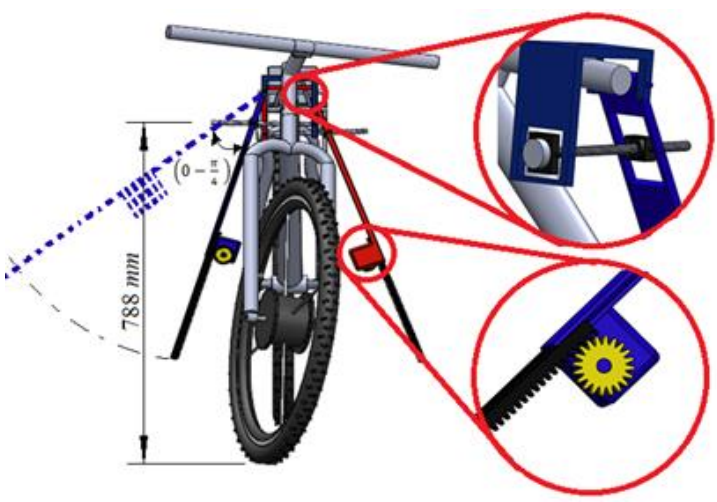

(b)

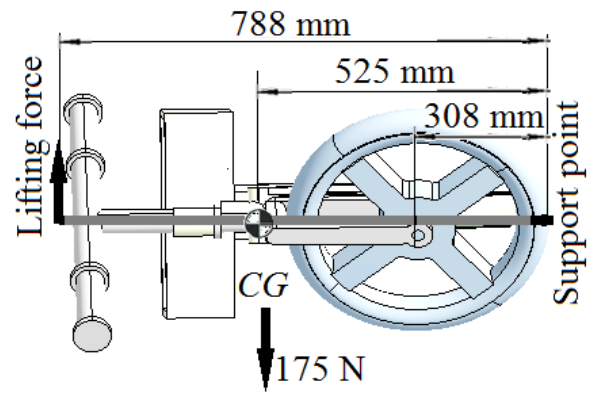

(c)

Figure 5. The arms (a) on the frame, (b) front view, (c) force equilibrium when it falls

The weight of the bicycle is $F=175 \mathrm{~N}$ and its vertical height is $788 \mathrm{~mm}$ at equilibrium position. By assuming that all weight are concentrated on its $\mathrm{CG}$, the moment required to rise a completely fallen bicycle up; $M=r * F=0.525 * 175$ $=91.875 \mathrm{Nm}$. So the force to be exerted by the pinion gear rack mechanism will be $F_{G R}=91.875 / 0.788=116.59 \mathrm{~N}$. It will consume $P=F * V=116.59 * 0.3=34.98$ Watt when its velocity is $\mathrm{V}=0.3 \mathrm{~m} / \mathrm{s}$. For the revolute joint, the ball screw mechanism will carry the same force too. Both will work sequentially. 


\subsubsection{Pinned levers driven by pneumatic pistons}

Pneumatically driven cylinders push the pinned lever to provide the reaction force from the lever-ground contact. Figure 6 gives two different configurations. The support levers equipped with two rotatable wheels bring the frame to its initial equilibrium position by their circular motion. Using four levers attached to the frame's various locations will satisfy that the frame will stay balanced both statically and dynamically during rising up.

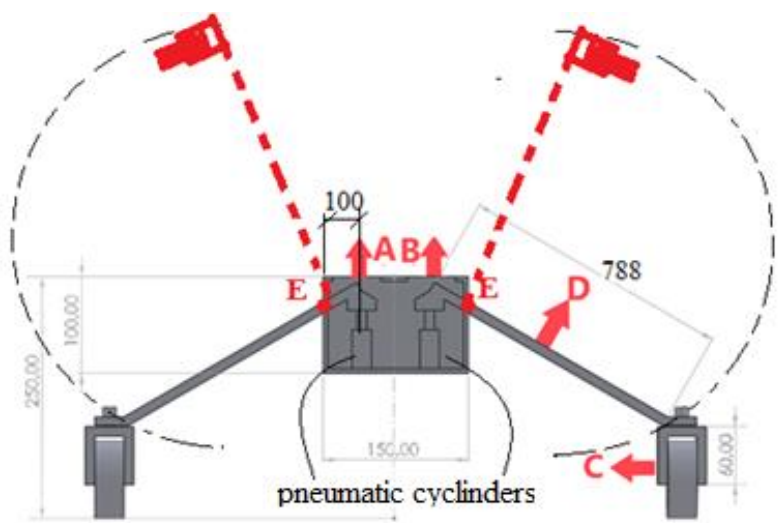

(a)

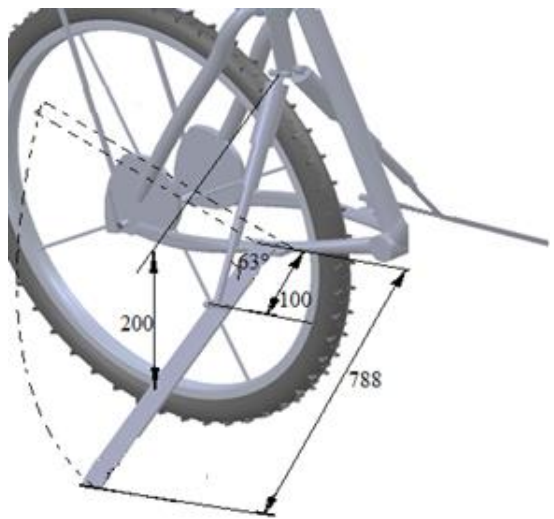

(b)

Figure 6. Pinned levers driven by pneumatic pistons (a) working envelope (b) its kinematics.

The lever rule gives the force requirement $F=83.83 \mathrm{~N}$ for both configurations. So the pressure required to carry this load should be $P=\frac{F}{A}=\frac{83.83}{0,0016848}=49755.02 P a=0.497$ bar when the total surface area of one piston $=0.0016848 \mathrm{~m}^{2}$.

\subsection{Structural analyses}

In this section, finite element analyses of the frame are performed to obtain the stress, deformation results and the moment requirements for the gyroscope with respect to time. Structural analyses are carried out statically and dynamically by using ANSYSC software [23].

\subsubsection{Static analysis}

The cases where loads are applied either steadily or slowly are analyzed by using static structural analysis. It verifies whether the applied load exceeds the yield strength.
Figure 7 shows the finite element model, applied loads, and boundary conditions. The loads consist of the frame's weight and additional $100 \mathrm{~kg}$ mass even designing additional mass is $5 \mathrm{~kg}$. Standard earth gravity is applied. Structural steel whose yield point is $300 \mathrm{MPa}$ is used as engineering material for the frame. In order to avoid mesher errors due to smaller dimension of the rim wires, rim wires are omitted in the model. Instead, the inner surface of the wheel rim and the outer surface of the hub shaft are connected as bonded contacts for both wheels. Figure 8 shows the deformation and stress results.

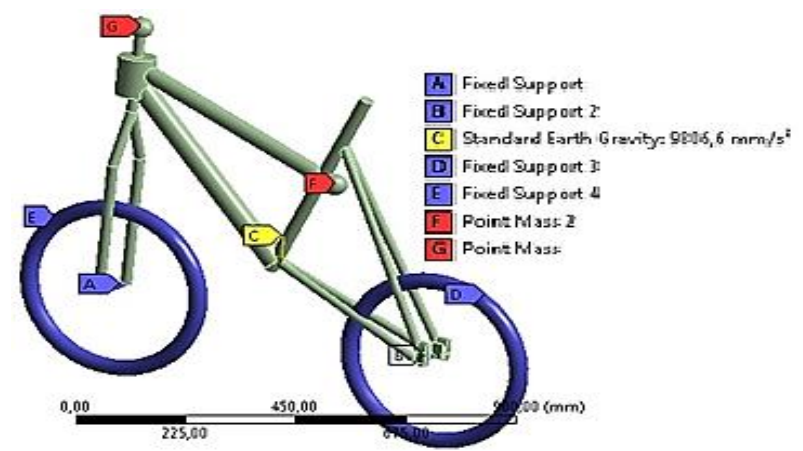

Figure 7. Load and boundary conditions applied to finite element model

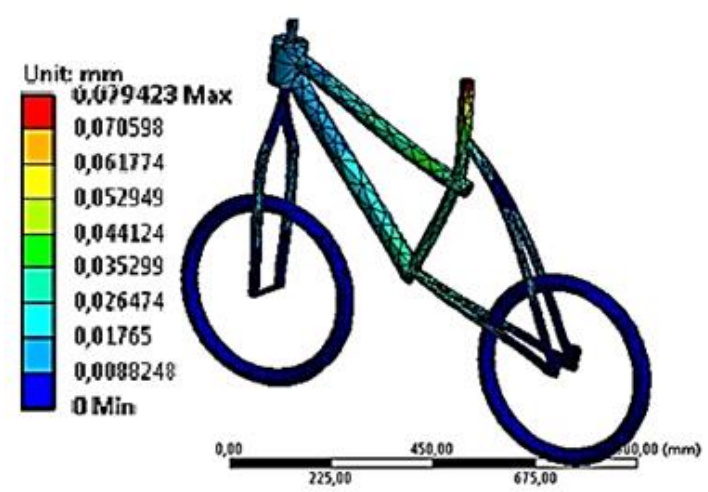

(a)

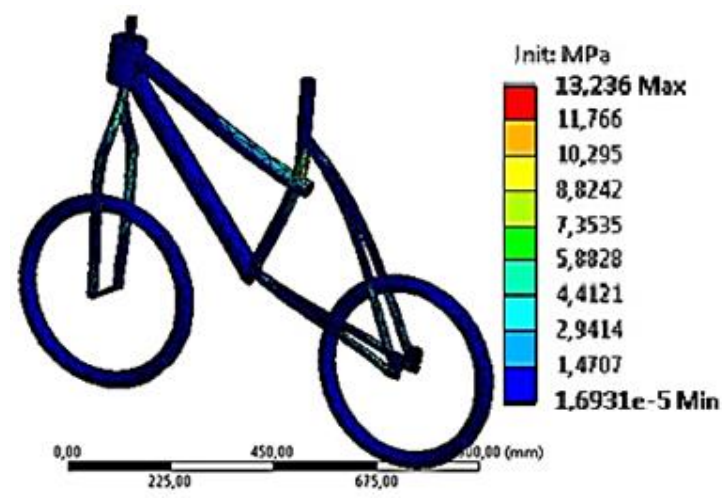

(b)

Figure 8. (a) Counterplot of deformation (b) the stress state 
It is seen that the biggest stress in the structure is 13.236 $\mathrm{MPa}$ which is far away from the yield point. The largest deformation is 29.23 microns. But in daily life, loads are not slowly applied to the structure. They may be time-dependent. So dynamic analyses are also performed to understand the response of the structure.

\subsubsection{Dynamic analysis}

The rear and front wheels are revolutionary connected to the frame. The handlebar is also fixed with the frame. A flat plate is used as a floor and it is fixed to the ground. As shown in Figure 9, the rotating surfaces of both wheels are connected to plate surface by rough contacts to simulate the road-wheel interaction. Other contact types (bonded, frictionless, no separation, forced frictional sliding) lead to undesirable conditions such as sliding, flying, turning and bouncing. Standard earth gravity is applied. Additional masses are applied at the points $A$ and $B$. At the beginning, the frame is set its vertical equilibrium position.

By means of that analysis, firstly, the maximum gyroscopic moment requirement is determined from the balance and torque history. Subsequently, the front/rear wheels will be driven sequentially to investigate if any influence on the gyroscopic moment. The analysis is repeated by changing the driving torque and additional masses.

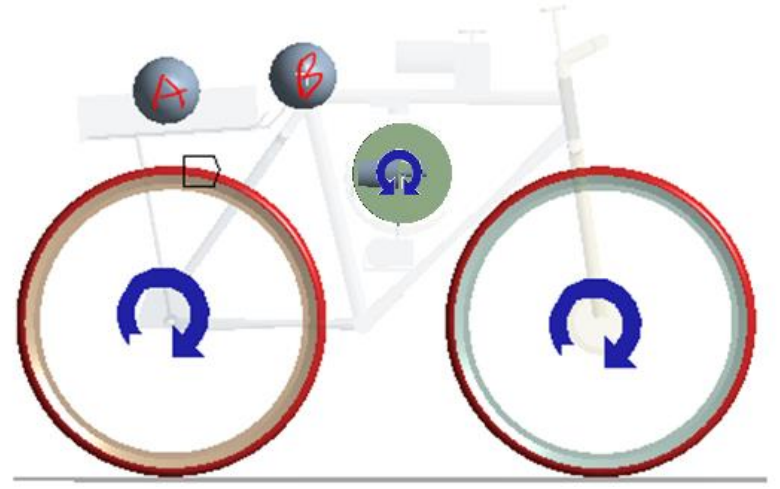

Figure 9. Contact surfaces between rear/front wheel and point mass loads, $A=B=2.5 \mathrm{~kg}$

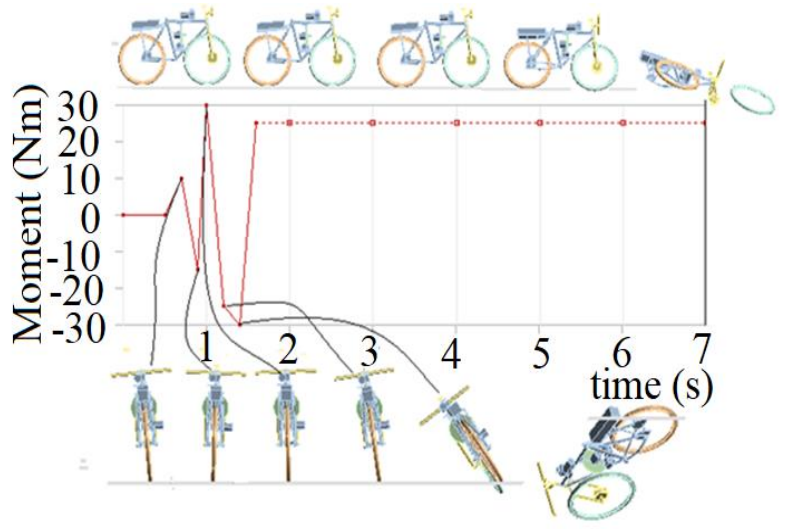

Figure 10. The gyroscopic moment history applied to the autonomous bicycle
It is seen that the bicycle continued to go forward by maintaining its equilibrium up to 0.7 second in the absence of any additional mass (the frame's own mass of $17.5 \mathrm{~kg}$ only). So $10 \mathrm{Nm}$ gyroscopic moment is applied and it leads the frame to come to equilibrium up to 0.9 second. It starts to tilt again toward opposite side. So $-11.8 \mathrm{Nm}$ gyroscopic moment is applied at 0.9 second. It leads the frame to equilibrium again. Eventually, $30 \mathrm{Nm}$ is applied to balance the frame and so on. In this way, the torque history given in Figure 10 is applied on the bicycle to prevent falling every time when the balance is disturbed. It is concluded that the maximum moment will be $30 \mathrm{Nm}$ to balance the frame.

\subsection{Gimbal design}

As a result of the dynamic analysis, the maximum moment requirement is determined as $30 \mathrm{Nm}$. So the $\mathrm{CMG}$ to provide that torque is designed based on Equation (6). The disk has to have constant mass value due to manufacturing limitations. When the given parameters are used, the gimbal will produce $32.84 \mathrm{Nm}$ as seen in Table 2 .

Table 2. Parameters of the gyroscope

\begin{tabular}{|c|c|c|c|}
\hline Parameters & Description & Value & Unit \\
\hline $\mathrm{P}$ & Disk rotation speed (spin) & 300 & rpm \\
\hline$\dot{\psi}$ & $\begin{array}{l}\text { Angular rate of gimbal of } \\
\text { CMG (precession) }\end{array}$ & 6 & $\mathrm{rad} / \mathrm{s}$ \\
\hline$\theta$ & $\begin{array}{l}\text { Gimbal angle of CMG (motion } \\
\text { angle) }\end{array}$ & 10 & derece \\
\hline$m$ & Mass of disk & 3.5 & $k g$ \\
\hline$r$ & Radius of disk & 8 & $\mathrm{~cm}$ \\
\hline$I$ & $\begin{array}{l}\text { Moment of inertia with respect } \\
\text { to the axis of rotation of the } \\
\text { disk }\end{array}$ & 0.0112 & $\mathrm{~kg} \cdot \mathrm{m}^{2}$ \\
\hline$I_{0}$ & $\begin{array}{l}\text { Moment of inertia of the disk } \\
\text { with respect to other axes }\end{array}$ & 0.0056 & $\mathrm{~kg} \cdot \mathrm{m}^{2}$ \\
\hline M & $\begin{array}{l}\text { Gyroscopic moment (from } \\
\text { Equation 6) }\end{array}$ & 32.84 & $N . m$ \\
\hline
\end{tabular}

\section{Results and discussions}

3.1 Relation between gyroscopic moment, spin, gimbal angle, and angular rate

Based on Eq. (6), how the spin $\mathbf{P}$, gimbal angle $\boldsymbol{\theta}$, and gimbal's angular rate $\dot{\boldsymbol{\psi}}$ influence on the gimbal moment $\mathbf{M}$ is calculated when $\Omega=\dot{\psi}=1,2,3 \mathrm{rad} / \mathrm{sec}$ at $\theta=10^{\circ}$ and $-10^{\circ}$ for $\mathbf{P}=0-3000 \mathrm{rpm}$. It is seen from the graphs in Figure 11 that the direction of the moment changes when the direction of precession changes. The relation between gyroscopic moment and flywheel spin is linear. The spin is getting increased, the moment increases as expected. Similarly, while the angular rate of gimbal is getting increased, it increases. 

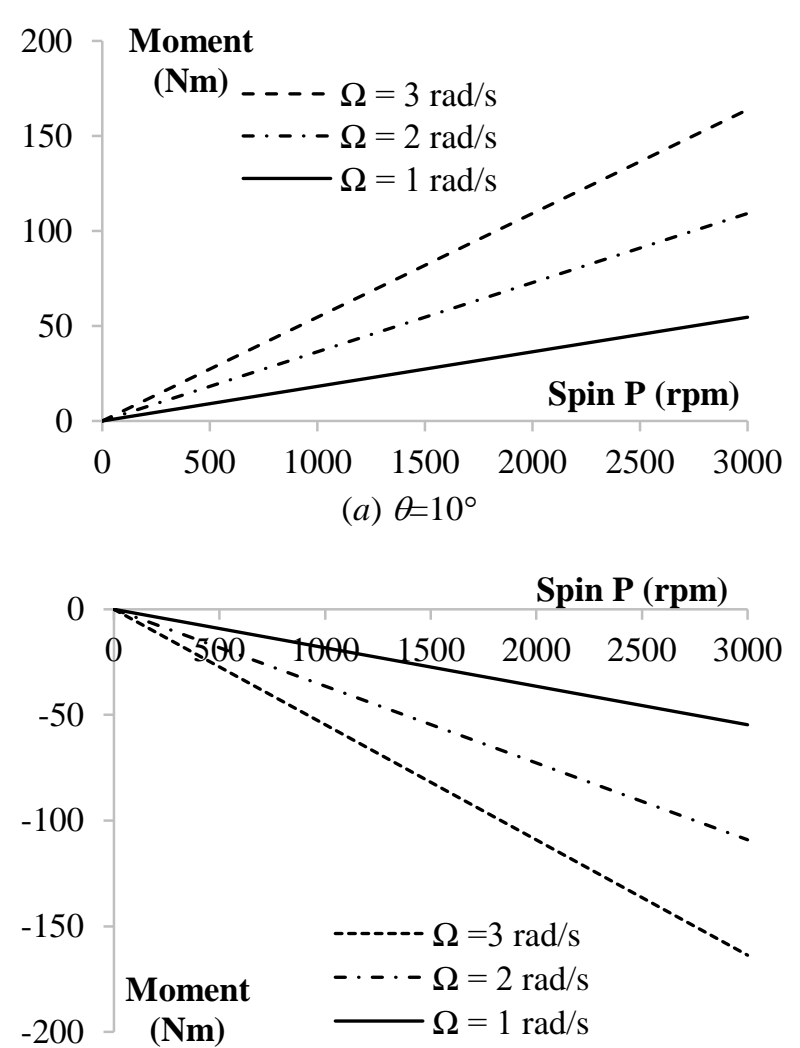

(b) $\theta=-10^{\circ}$

Figure 11. Gyroscopic moment versus spin for various gimbal rates

\subsection{Relation between load, gyroscopic moment and tilt angle}

In order to check and validate the results, data collected from finite element analyses are compared with those from literature. At the beginning, the frame is set its equilibrium position without any tilt angle and the bicycle is started moving. To check its balance, tilt angle is probed for different loading cases by adding point masses. In all cases the frame falls after a while. Stability is lost earlier than others in the case where the load is $1 \mathrm{~kg}$. While the weight is getting increased, the tilt from equilibrium point decreases contrary to expectations as in Figure 12. Park and Yi (2020) [17] can achieve a stationary balance. Their experimental bicycle model has just $2.36 \mathrm{~kg}$ mass and $148 \mathrm{~mm}$ length and gimbal angles between $-6^{\circ}$ and $7^{\circ}$. They use a linear quadratic regulation (LQR) algorithm for the gimbal motor control. Their models include double CMG. Load, dimension, and control method are main actors on balance. So its balance control is done easier due to lesser load, smaller dimension, and a control strategy. He and Zao (2015) [2] use the model having $9.77 \mathrm{~kg}$ mass and $660 \mathrm{~mm}$ length and gimbal angles between $-0^{\circ}$ and $28.65^{\circ}$. They use state feedback control. Active balance cannot be achieved without a control method.

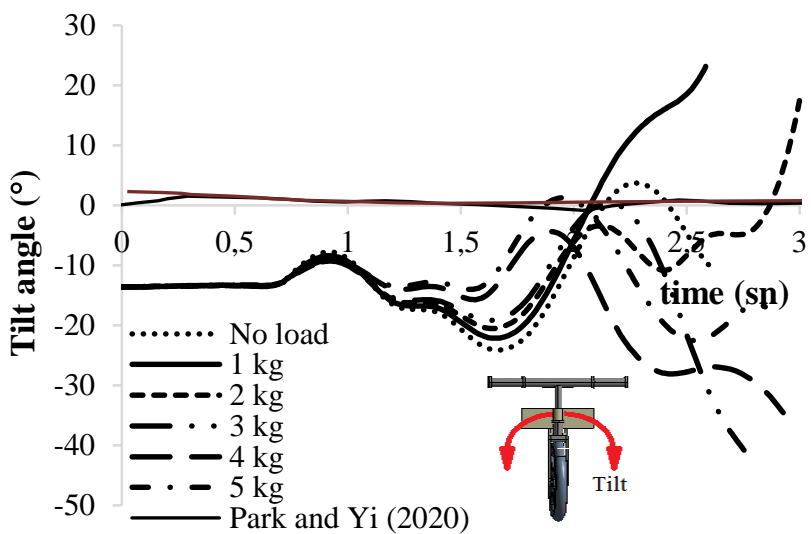

Figure 12. (a) Simulation results on tilt angle

Masses are located on both points equally. Figure 13 shows that the maximum gyroscopic moment requirement is getting increased as the additional load increases. In the case of $5 \mathrm{~kg}$ mass, the torque requirement is $30 \mathrm{Nm}$ and used for the CMG design.

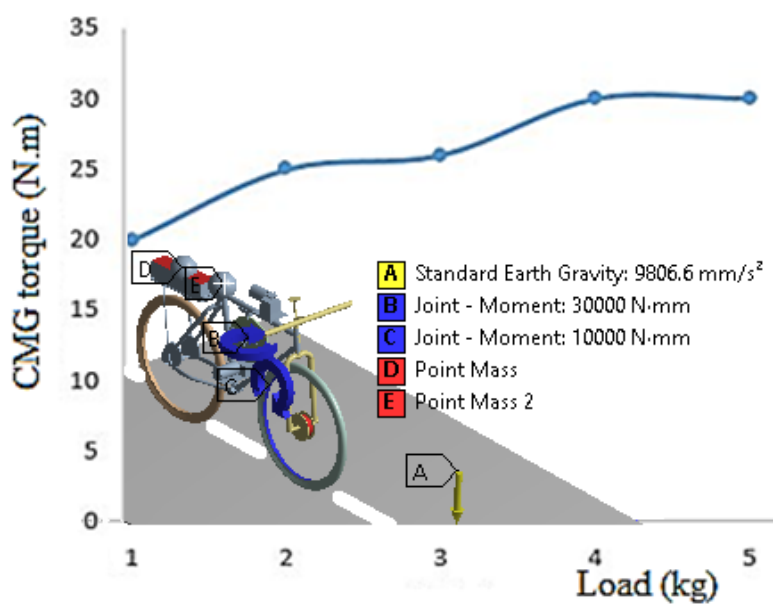

Figure 13. Maximum gyroscopic moment requirement for balancing with increased load

Rear and front wheels are separately driven and the effect of the drive torque on the gyroscope moment is also investigated. Whichever wheel is driven has no effect on the gyroscopic moment. Also driving torque doesn't have any effect on the gimbal torque as seen in Figure 14.

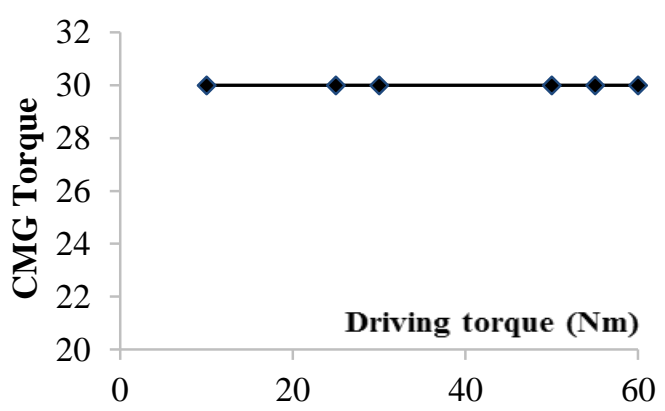

Figure 14. Effect of drive torque on gyroscopic torque 


\section{Conclusions}

In this study, a CMG with a single-axis gimbal is designed for a self-balancing bicycle including support and rising up systems. Structural analyses based on finite element simulation are performed to get the system's responses. The main conclusions of the study are as follows:

- The gyroscopic moment increases with increasing flywheel spin and angular rate of gimbal.

- Additional load leads the gyroscopic moment requirement to increase.

- Which one from the front or rear wheel drives the bicycle is not effective on the gyroscopic moment.

- Driving torque doesn't have any effect on the gimbal torque.

- The type of wheel-road contact must be set as rough. Other contacts lead to slip, fly, turn, and bounce.

- A control strategy is compulsory to achieve an active self-balancing.

Within the scope of this study, a CMG to be used for self-balancing is calculated and analyzed. Implementation of this study having a control algorithm will be performed as a future work.

\section{Acknowledgments}

The authors appreciate the valuable comments from the reviewers.

\section{Conflicts of interest}

The authors declare that they have no conflict of interests and competing interests regarding the publication of this paper.

\section{Similarity index: $5 \%$}

\section{References}

[1] H. Demirtaş, Robotik işleme yöntemi üzerine bir derleme. Niğde Ömer Halisdemir Üniversitesi Mühendislik Bilimleri Dergisi, 9(2), 1077-1089, 2020. https://doi.org/10.28948/ngumuh.600588

[2] J. He and Z. Mingguo, Control system design of selfbalanced bicycles by control moment gyroscope. Lecture Notes in Electrical Engineering, 338, 205-214, 2015. https://doi.org/10.1007/978-3-662-464663_21

[3] P. Y. Lam, Design and development of a self-balancing bicycle using control moment gyro. Master Thesis, National University of Singapore, Singapore, 49, 2012.

[4] A. V. Beznos, A. M. Formal'sky, E. V. Gurfinkel, D. N. Jicharev, A. V. Lensky, K. V. Savitsky, and L. S. Tchesalin. Control of autonomous motion of two-wheel bicycle with gyroscopic stabilisation. Proceedings of 1998 IEEE International Conference on Robotics and Automation, 3, 2670-2675, Leuven, Belgium, 1998. https://doi.org/10.1109/ROBOT.1998.680749

[5] M. Yamakita and A. Utano, Automatic control of bicycles with a balancer. 2005 IEEE/ASME International Conference on Advanced Intelligent
Mechatronics, pp. 1245-1250, Monterey, CA, 2005. https://doi.org/10.1109/AIM.2005.1511181

[6] Y. Tanaka and T. Murakami, Self-sustaining bicycle robot with steering controller. The 8th IEEE International Workshop on Advanced Motion Control AMC '04, pp. 193-197, Kawasaki, Japan, 2004. https://doi.org/10.1109/amc.2004.1297665

[7] T. M. B. Website. Murata Boy. https:// corporate.murata.com/en-sg/about/mboymgirl/mboy [Accessed: Sept 27, 2019]

[8] B. V. Melkoumian, New solutions for autonomous control and navigation. Sensors, Systems, and NextGeneration Satellites IX, 59781Q, 21 October 2005. https://doi.org/10.1117/12.614741

[9] L. Morine, T. O'Connor, J. Carnazza, H. Varner, and D. Poor, Control moment gyroscope gimbal actuator study. Endix Corp Teterboro NJ Eclipse-Pioneer Div, AD0801885, 1966. https://doi.org/10.21236/ad08018 85

[10] L. Arena, F. Piergentili, and F. Santoni, Design, manufacturing, and ground testing of a control-moment gyro for agile microsatellites. Journal of Aerospace Engineering, 30(5), 2017. https://doi.org/10.1061/ (asce)as.1943-5525.0000754

[11] C. Guo, Q. Hu, Y. Zhang, and J. Zhang, Integrated power and vibration control of gyroelastic body with variable-speed control moment gyros. Acta Astronautica, 169, 75-83, 2020. https://doi.org/ 10.1016/j.actaastro.2019.12.027

[12] S. Jia and J. Shan, Vibration control of gyroelastic spacecraft using input shaping and angular momentum devices. Acta Astronautica, 159, 397-409, 2019. https://doi.org/10.1016/j.actaastro.2019.03.062

[13] E. I. Druzhinin, Calculation of program control not generating singularities in gyrosystems. Journal of Computer and Systems Sciences International, 58(2), 260-269, 2019. https://doi.org/10.1134/s10642307190 20060

[14] G. Li, M. Lu, J. Y. Zhang, D. Y. Wu, and D. Z. Wei, Denoising of $1000 \mathrm{Nms}$ control momentum gyroscope. Guangxue Jingmi Gongcheng/Optics and Precision Engineering, 20, 117-124, 2012.

[15] F. Liu, F. Gao, W. Zhang, B. Zhang, and J. He, The optimization design with minimum power for variable speed control moment gyroscopes with integrated power and attitude control. Aerospace Science and Technology, 88, 287-297, 2019. https://doi.org/ 10.1016/j.ast.2019.03.028

[16] D. Sawyer Elliott, M. Peck, and I. A. D. Nesnas. Optimal solution for torque capability of control moment gyroscopes. 2019 IEEE Aerospace Conference Proceedings, 1-17, Big Sky, MT, USA 2019. https://doi.org/10.1109/ aero.2019.8742213

[17] S. H. Park and S. Y. Yi, Active balancing control for unmanned bicycle using scissored-pair control moment gyroscope. International Journal of Control, Automation and Systems, 18(1), 217-224, 2020. https://doi.org/10.1007/s12555-018-0749-7 
[18] M. Alshahadat, M. Zohaib, I. Hussain, and A. U. Rahman, Autonomous single track vehicle. 2nd International Symposium on Multidisciplinary Studies and Innovative Technologies (ISMSIT), 163-166, Ankara, Turkey, 2018. https://doi.org/10.1109/ ismsit.2018.8567283

[19] N. Tamaldin, H. Yusof, M. F. B. Abdollah, G. Omar, and M. Rosley, Design self-balancing bicycle. Proceedings of Mechanical Engineering Research Day 2017, pp. 160-161, Melaka, Malaysia, 30 March 2017.

[20] J. L. Meriam and L. G. Kraige, Engineering Mechanics: Dynamics. Wiley, 2012.

[21] S. Tamayo-León, S. Pulido-Guerrero, and H. CoralEnriquez, Self-Stabilization of a riderless bicycle with a control moment gyroscope via model-based active disturbance rejection control. 2017 IEEE 3rd Colombian Conference on Automatic Control (CCAC), 1-6, Cartagena, 2017. https://doi.org/10.1109/CCAC. 2017.8276434

[22] H. Yetkin, S. Kalouche, M. Vernier, G. Colvin, K. Redmill, and U. Ozguner, Gyroscopic stabilization of an unmanned bicycle. 2014 American Control Conference, 4549-4554, Portland, OR, 2014. https:// doi.org/10.1109/acc.2014.6859392

[23] Ansys, Theory Manual Version 9.0. ANSYS Inc.: Canonsburg, PA, USA., 2004. 